\title{
Nuevos espacios comunicativos para las organizaciones: las redes sociales
}

\author{
Begoña Gómez NieTo \\ Universidad de Valladolid, España \\ gomeznietob@hmca.uva.es; gomeznietob@gmail.com
}

\section{Resumen}

Internet ha modificado la forma de entender la comunicación en el actual contexto digital. El consumidor papel clave en todo este panorama comunicativo ha modificado su comportamiento, hábitos y pautas. Las organizaciones conscientes de ello se han visto obligadas a crear fórmulas para atraer su atención de forma eficaz y deberán utilizar todos los espacios donde esté el usuario.

Palabras clave: Organizaciones, redes sociales, contexto digital, comunicación

\section{New communicative spaces for the organizations: the social networks}

\begin{abstract}
Internet has modified the way of understanding the communication in the current digital context. The consumer key paper in all this communicative scene has modified his behavior, habits and guidelines. The conscious organizations of it have met bound to create ways to attract his attention of effective form and they will have to use all the spaces where the user is.
\end{abstract}

Key Words: Organizations, social networks, digital context, communication

Referencia normalizada:

Gómez Nieto, B. (2013) Nuevos espacios comunicativos para las organizaciones: las redes sociales. Historia y Comunicación Social. Vol. 18. Nºspecial Noviembre. Págs. 731-741.

Sumario: 1. Introducción. 2. Objetivos y metodología. 3. El reto de las empresas: comunicar desde la red. 3.1. Ventajas e inconvenientes de la publicidad en las redes sociales. 4. La apuesta de las organizaciones por la viralidad. 4.1. Medición del éxito de la viralidad. 5. Conclusiones. 6. Referencias bibliográficas.

\section{Introducción}

Desde la llegada de Internet a la vida de los ciudadanos, muchos son los cambios que se han producido: la forma de comunicarse entre las personas, la forma de estar informados, los hábitos en el consumo de medios, la manera de adquirir productos y servicios, etc. Las organizaciones conscientes de esta nueva realidad abren nuevos caminos y vías con el objetivo de impactar al usuario, llamar su atención y satisfacer sus necesidades y expectativas (Castelló, 2010:13). 
Las formas de actuar de los consumidores han cambiado y también su comportamiento ante los medios de comunicación. Los anunciantes conscientes de este cambio optan por nuevas formas de comunicación con sus distintos públicos. Las tradicionales inversiones en medios convencionales se han visto invadidas por apuestas hacia medios no convencionales y marginales hasta el momento ${ }^{1}$.

Según el informe de Infoadex del año 2013, la inversión en los tradicionales medios convencionales ha descendido $(42,6 \%)$ para ser superada por los medios no convencionales (57,4\%). A la cabeza de los medios convencionales se sitúa televisión con un $39,2 \%$ de participación en el conjunto de los medios convencionales, seguido de Internet. Este medio en pocos años ha pasado de ser un medio no convencional, por el que apostaban de forma tímida algunas empresas pioneras a ser núcleo principal de las inversiones publicitarias de muchos anunciantes. En este informe, Internet se posiciona por primera vez por encima del medio Diarios alcanzando la segunda posición por volumen de inversión en el conjunto de los medios convencionales. El porcentaje que Internet supone sobre el total de la inversión en el año 2012, en el capítulo de medios convencionales, es del 19\%, con un aumento de dos puntos y siete décimas en su cuota de participación. Y en este aumento tienen un hueco indiscutible los nuevos formatos publicitarios para las redes sociales ${ }^{2}$.

\section{Objetivos y metodología}

El objetivo del estudio se centra en el análisis de las redes sociales como nuevo soporte comunicativo-publicitario para las organizaciones.

Este análisis se trata desde diversos ángulos: económico (desde el punto de vista de negocio para empresas y profesionales de la comunicación), social (puesto que se han modificado pautas de comportamiento de los consumidores), cultural (este cambio ha supuesto la utilización de nueva terminología y la revisión de modelos, esquemas en el nuevo panorama mediático digital).

Se profundiza en la interrelación y los cambios producidos en ella entre los agentes implicados: el consumidor, las organizaciones, las redes sociales, las nuevas tecnologías, los medios de comunicación y la publicidad como factor generador de negocio. Se presentan la repercusión y las consecuencias que ha tenido la irrupción de Internet en todo este nuevo panorama comunicativo.

Como metodología, se desarrolla un análisis de contenido, aplicado a diversos artículos científicos de índole económica, social, mediática, extraídos de diferentes fuentes y referencias bibliográficas como queda detallado al final del estudio. 


\section{El reto de las empresas: comunicar desde la red}

Internet se consolida como el medio prioritario de entretenimiento para los españoles por delante de la televisión, una tendencia que se explica por el consumo cada vez mayor de ese medio para el visionado de televisión y para la lectura de artículos y noticias.

Según el estudio televidente 2.0 (séptima oleada), que analiza la evolución del ocio y el consumo audiovisuales en el hogar y en movilidad entre los internautas españoles, en los diferentes soportes y pantallas disponibles ${ }^{3}$, se reflejan las siguientes conclusiones: los dispositivos móviles modifican la pauta de consumo de contenidos; que el contenido se vuelve crítico en la competencia por la atención entre pantallas; que las aplicaciones (apps) de second screen despiertan expectativas positivas entre los usuarios; que la televisión social se acerca a WhatsApp; que vuelven a subir las descargas ilegales de contenidos: los sistemas P2P y las nuevas webs de enlaces disparan el consumo; que el consumo de contenidos mediante alquiler de títulos no logra arrancar; que el acceso online a los contenidos gratuitos de los canales de televisión consigue fidelizar al espectador a la parrilla; y que las aplicaciones de las smart TV se asientan para un consumo gratuito de contenidos.

Desde el punto de vista del marketing, la novedad reside en que el anunciante no solo contempla las redes sociales valorando la imagen que de ella tienen los usuarios, sino que las considera como un escenario en el que estar presente está más cerca de ser un imperativo que una opción. Victoria Más (2005:51) ratifica esta realidad incidiendo en como la red de redes se consolida como parte de la Integrated Communication Strategy, llevando la empresa a afrontar su labor comunicativa en redes sociales desde una visión global y holística.

Lo relevante pues, no son tanto los significantes utilizados para crear el imaginario del mensaje publicitario, sino la estrategia comunicativa seguida, el uso creativo de las herramientas de las que se dispone para reinventar un medio en el que el usuario es el centro, e incluso, crear nuevos soportes.

A este respecto debemos señalar que los usuarios de las redes sociales acogen de forma positiva que las marcas estén en la red. El 70\% de los usuarios de redes sociales se muestran receptivos a la presencia de marcas en este entorno ${ }^{4}$. Se identifican dos claras tendencias divergentes. Por un lado asistimos a un momento en que el entusiasmo por estas redes sociales pierde fuerza. En este sentido son Facebook y Tuenti las más perjudicadas. El fenómeno está motivado, en parte, por el impacto de WhasApp. Por otro lado, algunos factores como la extensión de dispositivos móviles, determinados movimientos sociales y la presencia de marcas en las redes mantienen viva la tendencia. Sin duda podemos decir que presenciamos la reconfiguración de las redes sociales. 


\subsection{Ventajas e inconvenientes de la publicidad en las redes sociales}

Las redes sociales son, sin lugar a dudas, el destino diario de millones de personas de todo el mundo. Si bien empezaron siendo un espacio en el que los usuarios podían conectar con gente de alrededor del planeta, pronto las empresas entendieron su valor y crearon sus propios perfiles. La idea era establecer un modelo de relación bidireccional con sus seguidores y fomentar el diálogo con la marca.

La entrada de marcas en las redes sociales fue aplaudida por los propios fundadores de las redes sociales. No sólo esto sino que, además, optaron por concederles un formato especial que los diferenciara del usuario particular y, poco a poco, han ido incorporando nuevas funcionalidades para facilitar su gestión. Pero este apoyo a las marcas no ha sido desinteresado sino que responde claramente a su estrategia de negocio. De aquí que el modelo publicitario se haya extendido en la mayoría de redes sociales existentes en la actualidad y que sus sistemas evoluciones con rapidez para adaptarse a las necesidades de los anunciantes ${ }^{5}$.

El gasto en publicidad en las redes sociales superará los 8.000 millones de euros en 2017. Con estos pronósticos, todo parece apuntar que el modelo publicitario en los canales sociales va viento en popa. De hecho, teniendo en cuenta el ritmo de crecimiento actual, se estima que a finales de 2013 Facebook ingrese cerca de 7.653 millones de euros en concepto de publicidad.

Por otro lado, cabe destacar que la publicidad en canales sociales ha tenido una gran acogida por parte de los profesionales del mundo del marketing. Según el último estudio realizado por MediaBistro, el $71 \%$ de agencias dicen usar los anuncios en medios sociales al mismo tiempo que los demás formatos de publicidad social, y el $41 \%$ afirma hacer un uso más intensivo en comparación con otras formas de publicidad offline. A continuación, presentamos las principales ventajas respecto a otras formas de publicidad online:

1. Potencial de segmentación: la ventaja principal de los formatos publicitarios de las redes sociales es la capacidad de segmentación que poseen. A diferencia de sistemas como Adwords, la publicidad social te permiten segmentar en función del perfil del usuario y su comportamiento en el canal. Esto es especialmente relevante en el caso de Facebook y LinkedIn ads, cuyos sistemas publicitarios te permiten escoger los criterios demográficos (edad, género, estudios, profesión, etc.) así como también preferencias (gustos en el caso de Facebook o grupos de interés en el caso de Linkedin).

2. Exige una inversión baja: exceptuando el caso de Linkedin, el CPC de este tipo de canales publicitarios suele ser bajo comparado con formatos similares de publicidad online. De hecho, según el último estudio que lanzó Facebook, el CPC medio en España es de 0.31 \$ y el CPM es de 0.08 \$.

3. Integración en un entorno social: como ya hemos dicho, las redes sociales son espacios en los que converge un gran volumen de tráfico diariamente. 
Aunque sólo uno de cada tres usuarios de redes sociales recuerda alguna campaña publicitaria publicada en las redes sociales, por lo general la publicidad en las redes sociales no suele desagradar a los usuarios. No obstante, cabe destacar que últimamente ha surgido una corriente contraria a la existencia de publicidad en redes sociales. A continuación, vemos los principales inconvenientes de la publicidad en redes sociales:

Las críticas a la publicidad en redes sociales suelen proceder de los propios destinarios de los mensajes publicitarios. Muchos de ellos alegan que la emergencia de la publicidad social contribuye a generar ruido dentro de estos canales y se percibe como un fenómeno invasivo, que amenaza la libertad de navegación. Sin embargo, a la pregunta "¿Estarías dispuesto a pagar por usar las redes sociales sin presencia de publicidad?", son pocos los que responden afirmativamente.

La publicidad en redes sociales no para de crecer y las previsiones son que, en los próximos años, va a consolidarse en su máxima expresión. Sólo es necesario examinar la rápida evolución que están viviendo los sistemas publicitarios de los principales canales sociales como es el caso de Facebook, Twitter y Linkedin. Agencias y empresas cada vez destinan mayor parte de su presupuesto a este ámbito y su confianza en el medio no para de crecer. Ante este panorama parece evidente que, por ahora, las ventajas del modelo publicitario en redes sociales se imponen a los inconvenientes que plantea.

Las redes sociales figuran entre los medios favoritos dentro de la estrategia de marketing on line de las marcas. E1 90\% de los anunciantes en medios sociales elige Facebook como primera opción ${ }^{6}$.

Entre los diferentes medios y soportes para anunciantes, las historias patrocinadas (sponshored histories) se convierten en el formato o tipo de anuncio más utilizado por las empresas y marcas en Facebook, elegidos por dos de cada tres anunciantes. Por otra parte, un $40 \%$ de los anunciantes apuesta por los anuncios corporativos tradicionales dentro de la red social, junto con el resto de opciones y productos promocionales disponibles $(30 \%)$.

Destaca el hecho de que más del doble de las empresas afirma ser capaz de medir el ROI (retorno de la inversión) de sus anuncios en las redes sociales, mientras que únicamente el $11 \%$ puede demostrar la eficacia de las promociones y acciones gratuitas dentro de las mismas. La estimación del ROI sigue siendo todo un reto para la mayoría de las empresas. Un 19\% incluso indica que no aprecia ningún retorno sobre la inversión realizada en ninguna de las acciones desarrolladas en las diferentes redes sociales.

En cuanto a la publicidad en el resto de redes sociales, más de la mitad de los anunciantes también incluye YouTube (55\%) o Twitter (53\%) dentro de su plan de medios digitales. Una de cada tres empresas también desarrolla acciones de pago en Linkedln. El 25\% también utiliza Google. 
El sector publicitario de los Social Media es todavía incipiente. La inversión en redes sociales ocupa todavía una pequeña porción del presupuesto total, aunque está previsto que aumente en los próximos años. El 58\% de las marcas destinan como máximo un $5 \%$ de su presupuesto a la publicidad en redes sociales, mientras que un $34 \%$ invierte hasta un $10 \%$.

E-Marketer estima que las redes sociales facturarán este año 2013, 4,18 mil millones de dólares, una cantidad que aumentará en 2015 hasta alcanzar los 6,45 mil millones.

\section{La apuesta de las organizaciones por la viralidad}

Cuando en 1994 una pequeña editorial americana publicó un libro titulado "Media Virus", lo cierto es que muy pocos supieron ver, al menos de entrada, el impacto que la publicación tendría para las nuevas generaciones de publicitarios y, obviamente, de consumidores de todo el mundo. Bajo una portada de imagen desafiante y colores chillones, el profesor Douglas Rushkoff explicaba a los lectores cómo algunos servicios gratuitos de correo electrónico -Hotmail o Yahoo! entre otros- añadían publicidad corporativa al mensaje saliente de los usuarios. Según Rushkoff, cada vez que ese mensaje llegaba a una persona "sensible" o interesada en la publicidad del servidor, ese usuario se "infectaba", es decir, acababa por dar de alta una cuenta propia de correo, infectando a su vez a todos aquellos usuarios a los que enviaba un mensaje a partir de ese momento ${ }^{7}$.

Según Sánchez y Pintado (2010:102), la viralidad es consecuencia de la adecuación y coherencia de una serie de elementos que se ha sabido mezclar de manera correcta o por azar y poner en el lugar correcto, condicionada por una serie de potenciadores y la elección o combinación de unas vías.

A pesar de que, sin lugar a dudas, el ejemplo español de publicidad viral más recordado es la campaña con que MTV hizo proclamar a millones de internautas que amaban a una chica llamada Laura, lo cierto es que hay diferentes tipologías de publicidad viral que, de forma similar a la convencional, suelen definirse en función de los objetivos de cada campaña. La más común es la que llama a la puerta de nuestro correo electrónico con un enfático “¡Pásalo!”: desde cadenas de correo auspiciando mala suerte ante la negativa de reenvío hasta peticiones económicas para causas humanitarias, pasando por los vídeos humorísticos con o sin un objetivo claramente publicitario.

Este es el formato elegido por muchas de las campañas publicitarias que, en los últimos años, han desbancado en efectividad a las formas de publicidad convencionales. "Amo a Laura" (http://www.youtube.com/watch? v=hRdVg_JATII), "Levántate ZP!" (http://levantatezp.blogspot.com/), ambas de Tiempo BBDO, o "No corras delante del oso" (http://festivals.doubleyou.com/2004/nikesansilvestre/web1/index.html), de la agencia catalana Doubleyou, serían algunos de los ejemplos de esta tipología. 
La viralidad incentivada, en segundo lugar, sería aquella que ofrece algún premio a cambio de aportar datos personales -propios o ajenos- a una empresa: vales de descuento, productos promocionales... dicha información es un preciado tesoro para aquellas compañías que utilizan la comunicación no convencional como forma de contacto con los potenciales clientes. Otra de las formas más frecuentes de viralidad publicitaria son las denominadas "estrategias teaser" o de intriga. En este sentido, la agencia encargada de la campaña realiza un especial esfuerzo para que el usuario no identifique en un primer momento que el mensaje que recibe forma parte de una estrategia publicitaria.

No tan vinculadas a la comunicación publicitaria, encontramos otras formas de viralidad en las bases de datos gestionadas por los propios usuarios. Facebook, Fotolog, o Classmates.com, entre otros, serían claros ejemplos de estas formas de "contagiar" mensajes; es decir: los usuarios utilizan las bases de datos ofrecidas por servicios on-line para gestionar su red de contactos. A partir de ahí, cada usuario invita a diferentes personas a formar parte de su comunidad que, a su vez, involucran a otros internautas para que se integren en el "club de miembros" iniciado por el primer usuario. Cabe señalar que, en este punto, la primera forma de viralidad a la que aludíamos -“¡Pásalo!”- y ésta última se acaban mezclando, ya que la mayoría de las campañas publicitarias difundidas a través de internet, una vez salen del servidor de correo de la agencia autora del mensaje, acaban por difundirse a través de las bases de datos personales de millones de usuarios, de manera que el efecto potencial de las mismas acaba multiplicándose hasta límites insospechados.

\subsection{Medición del éxito de la viralidad}

Dada la reciente irrupción de la publicidad viral en el panorama de las estrategias publicitarias, otro de los ejemplos que podríamos calificar ya de "histórico" es la acción viral que lanzó Unilever hace dos años para su marca Axe, con el objetivo de reforzar el impacto de una campaña de desodorantes puesta en funcionamiento en plena campaña navideña. La acción consistía en una tarjeta digital en la que se veía a una chica en bikini que sonreía o movía las partes de su cuerpo que el asombrado internauta decidía acariciar con el puntero del mouse. Dicha animación fue enviada a la base de datos de clientes que poseía Axe y, a su vez, los usuarios la reenviaron a su red de contactos, la cual, difundió la postal simultáneamente entre su propia red de amigos...De esta forma, Axe consiguió llegar a un volumen a priori insospechado de usuarios de características psico-demográficas similares, focalizando así el impacto del mensaje en el propio target del producto.

Cabe señalar, sin embargo, que el impacto de la comunicación viral no es fácilmente predecible y que, a la vez, la fórmula mediante la cual se calcula el éxito o el fracaso de una determinada campaña no suele ser del agrado, especialmente, del anunciante, por considerarla, en cierto modo, poco rigurosa: a mayor retorno al lugar de origen pasado un cierto tiempo, mayor éxito de la campaña. 
Tal como aseguran Kirby y Marsden (2007:79), "si un prospecto contagiado envía la misma publicidad mediante correo a más de un prospecto sensible (es decir, que la tasa de contagio base sea mayor a uno), los resultados estándares en epidemiología implican que el número de prospectos infectados crecerá según una curva logística". Los autores destacan que, en realidad, esta idea obedece a una función matemática que aparece en diversos modelos de crecimiento de poblaciones, propagación de enfermedades epidémicas y difusión en redes sociales, entre otros. Para ambos, esa función "constituye un refinamiento del modelo exponencial para el crecimiento de una magnitud dada".

Como consecuencia de esta formulación, resulta interesante ver cómo los propios internautas que reciben y que, a su vez, reenvían el mensaje. De acuerdo con los autores, si una campaña inicia su andadura enviando un mensaje a un mínimo de 100 usuarios, es necesario realizar una investigación de mercado para comprobar cuantos de ellos han reenviado el mensaje. Suponiendo que "esa cantidad equivale al 80 por ciento, 80 personas recibirán un mensaje reenviado de "primera generación". A partir de ahí, en cada generación siguiente los mensajes reenviados irán declinando más o menos de forma exponencial, de manera que cada una será menor que la anterior". Esta es, en realidad, la fórmula más utilizada por las agencias de publicidad y los departamentos de márketing para analizar en cifras el éxito o el fracaso de la viralidad de una campaña publicitaria.

A pesar de que el sistema de medición no acaba de satisfacer a las partes implicadas, es interesante calcular a la vez la proporción "inversión-impacto" de las campañas virales. Si bien el anunciante debe adjudicar un presupuesto inicial al envío de los primeros mensajes, lo cierto es que la viralidad asume el resto; es decir, los mensajes reenviados a partir de la segunda generación no suponen coste alguno para la empresa anunciante y, como contrapartida, cuando una de estas campañas sobrepasa la tercera generación de reenvío, el éxito de la misma suele estar garantizado ya que la mayoría de estudios de mercado demuestran que, hasta que un mensaje llega a su quinta generación de reenvío, el número de internautas que reciben el mensaje suele ser superior al de la generación anterior.

\section{Conclusiones}

Uno de los objetivos principales de las empresas es mantener la fidelidad del consumidor. Para ello no sólo debe impactar al consumidor con sus mensajes, sino que esos mensajes deben ser eficaces. En ese afán por llamar la atención, una de las herramientas cada vez más utilizada por organizaciones de diversa índole es la comunicación viral. La actual situación de saturación publicitaria a la que están sometidos todos los medios sin excepción, induce al anunciante a buscar salidas para hacer llegar el mensaje a su público objetivo. Los presupuestos publicitarios de las compañías se invierten en nuevos formatos que van más allá de la publicidad convencional. Es la 
metamorfosis del marketing, con versiones estelares altamente efectivas para la difusión del mensaje: el marketing viral es un claro ejemplo de ello. El marketing viral se define como un conjunto de técnicas que intentan explotar redes sociales preexistentes para producir incrementos exponenciales de conocimiento de marca. De esta forma, se consiguen sorprendentes efectos sin grandes inversiones ni contrataciones de medios masivos; es una manifestación distinta del genuino word-of-mouth -publicidad de boca en boca-, en donde la comunicación verbal se sustituye por otra a través de la red que hará posible generar cobertura mediática mediante historias inusuales. Esta práctica de comunicación comercial está siendo ampliamente usada por la necesidad de escapar de la actual situación publicitaria que se vive en los medios convencionales, caracterizada por la presencia masiva de mensajes comerciales ${ }^{8}$.

Si una organización quiere llegar al consumidor de forma eficaz a través de sus mensajes, no le queda otra que aceptar, adaptarse a los cambios tecnológicos existentes, tener presencia y gestionar ésta de forma óptima en las redes sociales.

El poder del consumidor ya está asumido. Aproximadamente 1.500 millones de personas se conectan diariamente a Internet, y habrá 1.000 millones más en los próximos cuatro años. Estas cifras, además de todas las ofrecidas, indican que el cambio es una realidad, y que una de las peculiaridades más sobresalientes de este escenario es que está siendo vivido en tiempo real. Internet como piedra angular del actual escenario de comunicación en el que estamos inmersos, Internet como motor de una nueva sociedad, de la red entendida como espacio social, como agente activo protagonista como nunca de un presente que desconcierta, cambia, y mueve a todos los agentes de un nuevo entramado con reglas que se descubren en ocasiones sobre la marcha.

Si existe crisis en cuanto a la reputación corporativa de las organizaciones, la realidad evidencia los efectos positivos sobre los negativos que implica esta sobreexposición de las marcas en el mundo digital.

\section{Referencias bibliográficas}

Libros

CASTELLÓ, Araceli (2010): Estrategias empresariales en la web 2.0. Editorial Club Universitario. Alicante.

SÁNCHEZ HERRERA, Joaquín y PINTADO BLANCO, Teresa (2010): Nuevas tendencias en Comunicación. Madrid. Editorial ESIC. Madrid.

VICTORIA MÁS, Juan Salvador (2005): Reestructuras del sistema publicitario. Ariel Comunicación. Barcelona.

MARTÍ PARREÑO, José (2005). Publicidad y entretenimiento en la web. Madrid: RA-MA.

RUSHKOFF, Douglas (1994). Media Virus. New York: Ballantine. 
KIRBY, Justin; MARSDEN Paul (2007). Connected Marketing: The Viral, Buzz and Word of Mouth Revolution. New York: Elsevier.

Artículos en revistas en papel

PINO ROMERO, CRISTINA DEL (2011). "Redes sociales, comunicación publicitaria y digital en la nueva era”. En: Revista Comunicación, n 9, vol. 1, año 2011, pp. 163-174. ISSN: 1989-600X.

Artículos en publicaciones web

Grupo Consultores (2008). Estudio de imagen de las agencias españolas 2008. En http://www.grupoconsultores.com [30/07/2013]

http://www.infoadex.es/InfoAdex_Resumen_Est_Inv_2013.pdf [25/07/2013]

http://www.informeticfacil.com/televidente-2-0-2013-vii-oleada-cocktail-analysis [23/10/2013]

http://tcanalysis.com/blog/posts/el-70-de-los-usuarios-de-redes-sociales-se-muestran-receptivos-a-la-presencia-de-marcas-en-este-entorno [22/10/2013]

$\mathrm{http} / / /$ comunidad.iebschool.com/iebs/general/pros-y-contras-de-la-publicidad-en-redes-sociales/ [22/10/2013]

http://www.puromarketing.com/16/18233/facebook-erige-tambien-como-reina-publicidad-redes-sociales.html [20/10/2013]

http://www.upf.edu/hipertextnet/numero-6/publicidad-viral.html [24/10/2013] http://revistas.ucm.es/index.php/PEPU/article/view/16500 [20/10/2013]

\section{Notas}

1 Pino Romero, Cristina del. Revista Comunicación, nº 9, vol. 1, año 2011, p.164. ISSN: 1989-600X.

2 http://www.infoadex.es/InfoAdex_Resumen_Est_Inv_2013.pdf. Fecha de consulta: 25/07/2013

$3 \mathrm{http} / / /$ www.informeticfacil.com/televidente-2-0-2013-vii-oleada-cocktail-analysis. Fecha de consulta: 23/10/2013

$4 \mathrm{http}: / /$ tcanalysis.com/blog/posts/el-70-de-los-usuarios-de-redes-sociales-se-muestran-receptivos-ala-presencia-de-marcas-en-este-entorno. Fecha de consulta: 22/10/2013

5 http://comunidad.iebschool.com/iebs/general/pros-y-contras-de-la-publicidad-en-redes-sociales/ $[22 / 10 / 2013]$

6 http://www.puromarketing.com/16/18233/facebook-erige-tambien-como-reina-publicidad-redes-sociales.html [20/10/2013]

7 http://www.upf.edu/hipertextnet/numero-6/publicidad-viral.html [24/10/2013]

8 http://revistas.ucm.es/index.php/PEPU/article/view/16500 [20/10/2013] 


\section{La autora}

Begoña Gómez Nieto es Doctora en Ciencias de la Información por el IE Universidad de Segovia (2008). Profesora Acreditada por la ANECA (Agencia Nacional de Evaluación de la Calidad y Acreditación) y ACSUCYL (Agencia para la Calidad del Sistema Universitario de Castilla y León) desde marzo y abril 2012 respectivamente. Licenciada en Publicidad y Relaciones Públicas por el Colegio Universitario de Segovia, UCM (1995). Actualmente es profesora del grado de Periodismo en la Facultad de Filosofía y Letras de la Universidad de Valladolid. Además de las tareas docentes, ha desempeñado en otras universidades labores de gestión, coordinación de cursos, dirección de proyectos de fin de carrera, etc. Entre sus publicaciones destacan varios artículos fruto de sus líneas de investigación centradas en el ámbito de la comunicación corporativa, comunicación publicitaria y nuevas formas de comunicación publicitaria (ambient marketing, flagships, redes sociales, estructura de contenidos en webs,...). 